\title{
Urban Mobility Social Networks as Valid Sources for Collaborative Consumption Research
}

\author{
Juan C. Correa \\ Consumer Psychology Graduate Program, Fundación Universitaria Konrad Lorenz \\ Bogotá, Colombia
}

\begin{abstract}
Surveys and experiments are the standard data sources for consumer behavior research. As a consequence, few studies illustrate the relevance of social networks as a third data source. The aim of this paper is to provide a rationale on why social networks can be both scientifically useful and socially relevant for consumer research. The urban mobility of Bogotá, as a case study for collaborative consumption research, illustrates the use of novel variables and possible ways to analyze them for theory building. The paper discusses the implications of these data sources for future theoretical development.

Keywords: Uber, Twitter, Google Maps, Consumer Research, Urban Mobility, Transformative Consumer Research
\end{abstract}

A common cliché nowadays goes like this: "Exciting developments in interactive Internet technologies are transforming the way marketers and consumers speak to one another." (Englis, Solomon, \& Danskin, 2005, p.491). This statement, however, reflects the essence of new business models like Uber which are based on the so-called "collaborative consumption" (Möhlmann, 2015). According to S. Benoit, Baker, Bolton, Gruber, and Kandampully (2017), collaborative consumption is different from other more traditional forms of exchange, as it entails a triadic interaction among a platform provider that enables the exchange, a customer who seeks access to tangible or intangible resources and a peer service provider who grants it.

Since collaborative consumption takes place inside a platform whose providers promote as virtual social communities (Möhlmann, 2015; S. Benoit et al., 2017) the use of computational methods to obtain and analyze data from these social communities becomes natural. In fact, this idea would be no unexpected to distinguished scholars who are aware of the role of Internet on consumer decisions (Henry, 2005; Lynch et al., 2015; Simonson, 2015). The description of novel methods for studying consumption phenomenon is always a timely topic for the field as recent studies have shown (Figueiredo \& Scaraboto, 2016; Scaraboto, 2015). However, consumer research focused on urban mobility has been rather scarce, being Bardhi and Eckhardt (2012) or Correa and Forero (2017) recent exceptions. 
Apart from the use of traditional survey-based methods (Hamari, Sjöklint, \& Ukkonen, 2016), there are two methodological approaches for studying collaborative consumption. A first approach, known as "netnography", is useful to study cultural practices of social media (Kozinets, 2015). A second approach, commonly known as "Big Data" groups a set of procedures to extract patterns and knowledge from large amounts of data (Landers, Brusso, Cavanaugh, \& Collmus, 2016). Although netnoraphy and big data are already used in consumer research (Kozinets, Patterson, \& Ashman, 2016; Gopaldas, 2014), big data techniques are increasingly present in different journals of business and social sciences, given their usefulness for analytic and practical purposes in decision-making (Cheung \& Jak, 2016; E. E. Chen \& Wojcik, 2016). In fact, Simonson (2015) has recently acknowledged that the use of secondary data sources (like those coming from the Internet) often requires the ability to work with much bigger data sets than the typical experimental results, so "collaborations between behavioral and quantitative researchers in marketing need to receive higher priority" (p. 30). In fact, Lynch, Alba, Krishna, Morwitz, and Gurhan-Canli (2012) have claimed that consumer researchers "can avail themselves of data-mining" (p. 479).

The truthfulness of the data is an important issue associated with the use of these big data techniques. This idea is easy to understand in comparison with the three dimensions of big data (or the 3V's): "volume", "velocity" and "variety". According to Cheung and Jak (2016) volume relates to the size of the data set which may lead to problems with storage and analysis. Velocity refers to the speed of information production and its corresponding processing (which is needed as fast as possible). Variety of data refers to different information formats, often unstructured, such as mixtures of text, pictures, videos, and numbers. Despite the existence of online resources for managing big data dimensions (e.g., databricks.com), the veracity of data remains as a data quality concern.

Cheung and Jak (2016) claimed that "with big data, it may be even more important to consider whether the conclusions based on the data are valid than with carefully obtained smaller datasets" (p. 2). This advice requires specific considerations when it comes to defend the use of urban mobility social networks as valid sources for collaborative consumption research. Anderson et al. (2013) posited the relevance of urban mobility for consumer research as follows: "to become more sustainable in the future, cities (...) could benefit from transformative service research that focuses on rethinking how services such as (...) transportation (...) are delivered and consumed." (p. 1209). A first step before rethinking these services requires that consumer researchers understand how such services work from the consumer point of view as a decision-maker. Here is where the role of Uber, Twitter, and Google Maps emerges. The aim of this paper is twofold: Firtsly, it provides a rationale on why these platforms are useful resources for understanding urban mobility as a collaborative consumption phenomenon not based on the traditional notion of ownership. Secondly, it shows a step-by-step guidance for extracting and analyzing available data from these sources and illustrates its potential use for theorizing. The remainder of this paper is organized as follows. The next section presents the computational tools that might be used for exploring urban mobility with data obtained from these social networks. Then, the case study is described before the section of materials and method, which is followed by the results and a final discussion with its implications for future theoretical development. 


\section{Computational Tools for Exploring Urban Mobility through Social Networks}

Despite their differences, Uber, Twitter and Google Maps can be understood as "urban mobility social networks". In other terms, they are valuable sources of data that might be of help to understand urban mobility in any city. Let us illustrate this by describing previous research that shows the utility of these networks.

Hawelka et al. (2014) were one of the first in using Twitter as a data source for tracking global mobility patterns. Based on a data set of almost a billion tweets recorded in 2012, they estimated the volume of international travelers by country of residence. The community structure of the Twitter mobility network revealed spatially cohesive regions that follow the regional division of the world. The validation of these results were done by using global tourism statistics and mobility models provided by other authors. Hawelka et al. (2014) argued that Twitter is exceptionally useful for understanding and quantifying global mobility patterns. A drawback with this use of Twitter data is that geo-located tweets (tweets that include instant positions based on GPS feature activation) are not so common at the city scale. However, the semantic content of their messages is still valuable as it grasps public opinion about particular conditions of traffic flow, infrastructure or delivered services (such as the dragged off passenger David Dao in a recent case of a United Airlines flight).

A suitable software that can be used for massive retrieving of Twitter data is the "twitteR" package which was recently developed by Gentry (2015) and has also been used for other topics such as ideological consumerism in political campaigns (Correa \& Camargo, 2017). This software was designed as a mean to interact with the Twitter API (Application Programming Interface) to retrieve the profile of users as well as their recent tweets in convenient data frames through the $\mathrm{R}$ environment ( $\mathrm{R}$ Core Team, 2017). A relatively novel use of this data source consists of retrieving sets of massive tweets containing words related to transportation city services and identify most common words or ideas about it. This sort of analysis is easy to conduct with the aid of text mining software that allows identification of common patterns in textual data (K. Benoit et al., 2017; Meyer, Hornik, \& Feinerer, 2008).

The second data source is Google Maps. Kahle and Wickham (2013) also developed a software known as "ggmap" that allows the user to access the information provided by Google Maps through its API by using the $\mathrm{R}$ environment ( $\mathrm{R}$ Core Team, 2017). The user can request a map located in any part of the world and define its granularity or level of detail, which goes from the street scale to the planetary scale. Additionally, the functions "geocode", "Google Distance Matrix", and "Route" might be useful as well. The geocode translates nominal locations, such as "John F. Kennedy International Airport", into its corresponding longitude/latitude coordinates in decimal degrees. The distance Matrix function provides distances for Google-determined routes for driving, bicycling, or walking and their estimated travel times in a convenient format of data frame ready to use for further analyses. Finally, the route function provides a path that illustrates the origin and destination of a travel following the city infrastructure. A recent study that used this software consisted of analyzing and comparing several European "Bike Sharing Systems" as means of sustainable intermodal transportation to identify their potential issues in the future (Bouveyron, Côme, Jacques, et al., 2015). 
Uber is perhaps the platform with major apparent relevance for understanding urban mobility as a collaborative consumption phenomenon that emerges as a result of public transportation deficiencies and consumers changing needs. Collier and Wu (2017) recently developed a software known as "ubeR" package that allows its users to interact with Uber API also inside the $\mathrm{R}$ environment ( $\mathrm{R}$ Core Team, 2017). With this software, the user can know an estimated price range for travels with their corresponding start and end locations, the uber products offered at a given point of the city, as well as a list of user's payment methods. Given the recent launching of this software, we are not aware of any study that already has used it for studying urban mobility. Nonetheless, one of the first studies about Uber was conducted in the USA with data directly provided by the Uber research staff (Cramer \& Krueger, 2016). The results showed that the percent of miles driven with a passenger in Los Angeles and Seattle was higher for UberX drivers than for regular taxi drivers. Cramer and Krueger (2016) claimed that one of the reasons that explains this result is that Uber utilizes a more efficient driver-passenger matching technology based on mobile Internet technology and smart phones than do taxis. And a second reason is that Uber currently has more driver partners on the road than the largest taxi cab company operating in those cities. An important concern about Uber operations relates to safety, "with some in the taxi industry claiming that ridesharing is less safe than taking a traditional taxicab" (Feeney, 2015, p. 1). But, "the rapid growth of ridesharing provided by Uber, Lyft, and other companies demonstrates that consumers are far from fully satisfied with existing taxi service" (Feeney, 2015, p. 10-11). These statements show how citizens' transportation needs are changing as information technologies facilitate their interaction with transportation providers.

Uber's fares are dynamically priced based on the estimated time and distance of the route, the estimated traffic density, as well as the number of riders and drivers using Uber at a given moment. In addition, Uber shows the competitive advantage of offering different products that suit different mobility needs. The original Uber product consists of Uber drivers offering their services as traditional taxi cabs. The UberX product allows anyone to drive for Uber using their own car, subject to a background check and car requirements. The uberBICI product allows bikers to request a Uber vehicle equipped with bike racks and carriers so they can shift from a non-motorized transportation mode to a motorized one without leaving the bicycle behind. This product is quite convenient for cities like Bogotá where bicycles are also frequent transportation means. The uberPOOL product matches riders with another rider who is traveling in the same direction and the app will share the first name of the other rider and the planned route. The price for this service is less than all other Uber products and can be seen as an alternative to public transportation, though in a minor scale. Finally, the UberVAN product is similar to the UberX but it allows the simultaneous transportation of up to six passengers. Although these services are not available in all cities and countries, Uber provides an exceptional case for studying urban mobility as a collaborative consumption phenomenon which remains unstudied in the literature. In order to fill this gap, here we show the urban mobility of Bogotá as a case study that illustrates the sort of data available in these platforms and its potential use for theorizing on collaborative consumption. 


\section{The Urban Mobility of Bogotá as a Case Study}

As the city capital of Colombia, Bogotá presents one of the less satisfying driving indexes of the world (see its rank on the web page of the "Waze Driver Satisfaction Index").

According to previous research, the average one-way commute in Bogotá was 90 minutes (Gakenheimer, 1999) and this is one of the main causes of worker absenteeism in the city (Restrepo \& Salgado, 2013). Such fact might be due to the increasing vehicle sales which is a consequence of both the economic growth and the social pressure of owning a car as an essential asset (Gakenheimer, 1999). Between 1995 and 2000 citizens of Bogotá faced several changes in their urban mobility. For instance, Montezuma (2005) pointed out the achievements on road infrastructure, especially the implementation of paths exclusively reserved for cyclists, the revitalization of parks and sidewalks, and the implementation of the "Transmilenio" bus rapid transit system which has been successful in reducing traffic congestion while promoting walkability as a regular behavior to reach bus stations.

Despite these achievements, Bogotá is still facing problems in their urban mobility, specially when it comes to transforming its decentralized bus transit services into its integrated transit systems (Kash \& Hidalgo, 2014). Parra and Lemoine (2017) recently pointed out several problems. In first place, a funding issue that hinders Transmilenio is the overcrowding that passengers face because of the reduced number of buses compared to the number of passengers during rush hours. The elimination of many traditional routes occurred before the creation of substitutes which explains why the average trip on the Transmilenio system during peak hours went from 52 minutes in 2005 to 90 minutes in 2011. In second place, the quality of the Transmilenio buses remains outdated, as these diesel-based buses, purchased in 2001, continue to pollute the atmosphere along with their feeder buses, also known as SITP ("Sistema Integrado de Transporte Público"). In third place, the cost of passenger fares represent one-sixth of a local minimum wage salary (approximately US\$50 per month out of a salary of US\$318), which makes it the fifth most expensive public transportation system in Latin America (Parra \& Lemoine, 2017).

Apart from funding the construction and enhancement of current infrastructure of Transmilenio (Parra \& Lemoine, 2017), transportation planners should integrate the concerns of the community in the planning process, and this implies detecting incompatibilities between users' self-identified needs and the management of public transportation projects (Kash \& Hidalgo, 2014). The aim of this paper does not consider this complex task. Instead, it shows an approach that researchers might use not only in working with transportation planners and policy-makers but also for theorizing on urban mobility as a collaborative consumption phenomenon that emerges as the result of public transportation deficiencies. Given the fact that in Bogotá there already exists a public institution whose duties focus

on the improvement of urban mobility and transportation safety, this approach might be useful as well.

\section{Unexplored metrics of urban mobility and collaborative consumption}

Beyond the possibility of analyzing consumers' activities in terms of how actively/passively consumers behave online (Heinonen, 2011), other possibilities remain unknown. The public opinion about transportation services in a city can be understood as a specific word-of-mouth (WOM) (Hennig-Thurau, Gwinner, Walsh, \& Gremler, 2004) easily 
observed in urban mobility social networks. In consumer research it is well-known that WOM is an important factor that motivates consumers to transact goods and services in both traditional and electronic commerce channels (Hennig-Thurau et al., 2004). Roughly speaking, WOM refers to an oral, every day, and person-to-person conversation between two or more individuals. The topics of this conversation might encompass a brand, a product, a service or an organization. EWOM is a WOM system that exists in virtual space in which messages are sent or received related to products or services, and which users experience through chatting or online boards. In the case of urban mobility, these EWOM might shed lights on users' most common concerns and opinions about transportation mode choices in a city.

As Twitter provides a convenient means to communicate opinions of this sort, then consumer researchers might exploit the benefits of using Twitter API to extract large and almost-instantaneous datasets of commuters tweets. As the so-called "sentiment analysis" techniques allow researchers to identify, categorize and score positive, negative, or neutral opinions towards a particular topic (Danneman \& Heimann, 2014), commuters' voluntary declared preferences and attitudes might be revealed as well (e.g., why Uber is preferred than traditional taxis, or the acceptance of ride-sharing practices). The potential benefits of observing urban mobility practices by these means are undeniable for both academicians and policy-makers (Heinonen, 2011). Nonetheless, this requires a more interdisciplinary collaboration with data scientists who will facilitate the adoption of these techniques by consumer behavior scientists.

The daily, weekly or monthly evolution of dynamic Uber fares is another possibility that might unveil unexplored relationships like the impact of weather and traffic conditions on commuters' transportation mode choice (e.g., UberBICI, UberX, etc.) or Uber customers preferences. The possibility of estimating commuting costs, and tracking estimated travel times through Uber and Google Maps APIs, respectively might be useful for transportation regulators, who in turn, might play an important role in the future of transformative service research (Anderson et al., 2013). Here consumption refers not only to the exchange of money between users of collaborative consumption platforms (the Uber driver and the Uber client) but also to the exchange of valuable information that may be used to impact mobility patterns at a city scale. For example, as Uber clients know in advance travel time estimations which are used to calculate Uber fares, then both Uber drivers and clients might change originally planned routes in order to avoid traffic congestion and optimize dynamic travel fares. As Uber customers can also rate Uber drivers by sharing service ratings and EWOM, this information can be used as a sign of service reliability and trust on the service provider.

The need to differentiate between real EWOMS (i.e., generated from real customers) from fake EWOMS (generated by bots designed to automatically propagate garbage information) is another interesting venue virtually unexplored in consumer research (K. Chen, Luo, \& Wang, 2017; Forelle, Howard, Monroy-Hernández, \& Savage, 2015). Virtually all the research dedicated to the role of EWOM on online consumers assumes that these written transactions are indeed valid, as they are generated in the so-called Web 2.0 where the user-generated content is also visible by the members of a community (Huang \& Benyoucef, 2013). Nonetheless, this assumption requires further considerations when EWOMS are observed in social networks like Facebook, Twitter or Instagram, as these networks have been 
recently used for advertising purposes (Lee, Hosanagar, \& Nair, 2018; Evans, Phua, Lim, \& Jun, 2017). In order to illustrate how the preceding ideas might be implemented, we conducted a series of observations that might be relevant for further studies focusing on the relationship between urban mobility and consumer research (Correa \& Forero, 2017).

\section{Materials and Method}

Since the Transmilenio system plays a crucial role as a public transportation mode in Bogotá (Parra \& Lemoine, 2017), we built a first data set with the public opinion of Twitter users who spontaneously mentioned this Bogotan specific word between May 27 and June 5, 2017. We employed the function "searchTwitter" of the twitteR package (Gentry, 2015) to download a set of 15,000 tweets containing the word "Transmilenio". Since all these tweets were written in Spanish, we followed the text-cleaning procedure reported by Correa and Camargo (2017). This procedure consists of removing HTML tags, punctuation marks, mentions (Twitter usernames preceded by the "@"), and hashtags (thematic words preceded by the "\#") while preserving accented Spanish vowels given their relevance in Spanish language. To prevent misleading conclusions regarding most frequent comments of Transmilenio, we removed retweets from the original data set. Thus, the resulting sample $(\mathrm{n}=6,863)$ only contains unique tweets. We structured each of these tweets as a linguistic corpus with the aid of the "tm" package which is a handy tool for conducting text mining analysis (Meyer et al., 2008). In order to know most frequent comments regarding Transmilenio, we estimated "collocation statistics" (i.e., most frequent combined words) with the aid of the "quanteda" package (K. Benoit et al., 2017), a recent software development that complements the functions of the "tm" package. In a linguistic corpus, a collocation refers to a sequence of words that co-occur more often than would be expected by chance, so they are convenient for identifying regularities in public opinion.

We also built a second data set that contains a query with the Uber prices from Transmilenio stations to malls of Bogotá in June 5, 2017. This data set contains the name of each Transmilenio station (as provided in its official web site), the name of the main Bogotan malls with commercial operations in the city with their corresponding geographic coordinates in decimal degrees. We obtained the geographic coordinates of these places by employing the function "geocode" of the ggmap package (Kahle \& Wickham, 2013). The prices of currently available Uber services were queried through the Uber API and the ubeR package (Collier \& Wu, 2017). All data sets, packages, functions and instructions to replicate the results of this paper are currently available in the following online repository.

\section{Results}

Figure 1A shows the daily Twitter users' activity (i.e., number of tweets containing the word Transmilenio) produced by a sample of 4,012 Twitter users between May 27 and June 5, 2017. This activity was not higher than 500 tweets per day. However, on June 2 there is an exceptional peak resulting from the propagation of three different tweets by the same set of Twitter users at exactly the same hour. Such an activity seems to be articulated by a bot or software app that allows its users to copy tweets across multiple Twitter accounts (e.g., Zapier). The contents of these tweets are depicted in 1B as double and triple collocations. The first five collocations report words sequences that are common 
among Transmilenio users as they reflect some of the most typical features associated with this massive transportation system: "rutas fáciles" (easy routes), "puentes transmilenio" (transmilenio's bridges), "transmilenio venga" (come to transmilenio), "transmilenio sitp". In addition, the rest of collocations contain the word "inseguridad" (unsafe) which is also another word that describes the user experience in this system (Parra \& Lemoine, 2017).
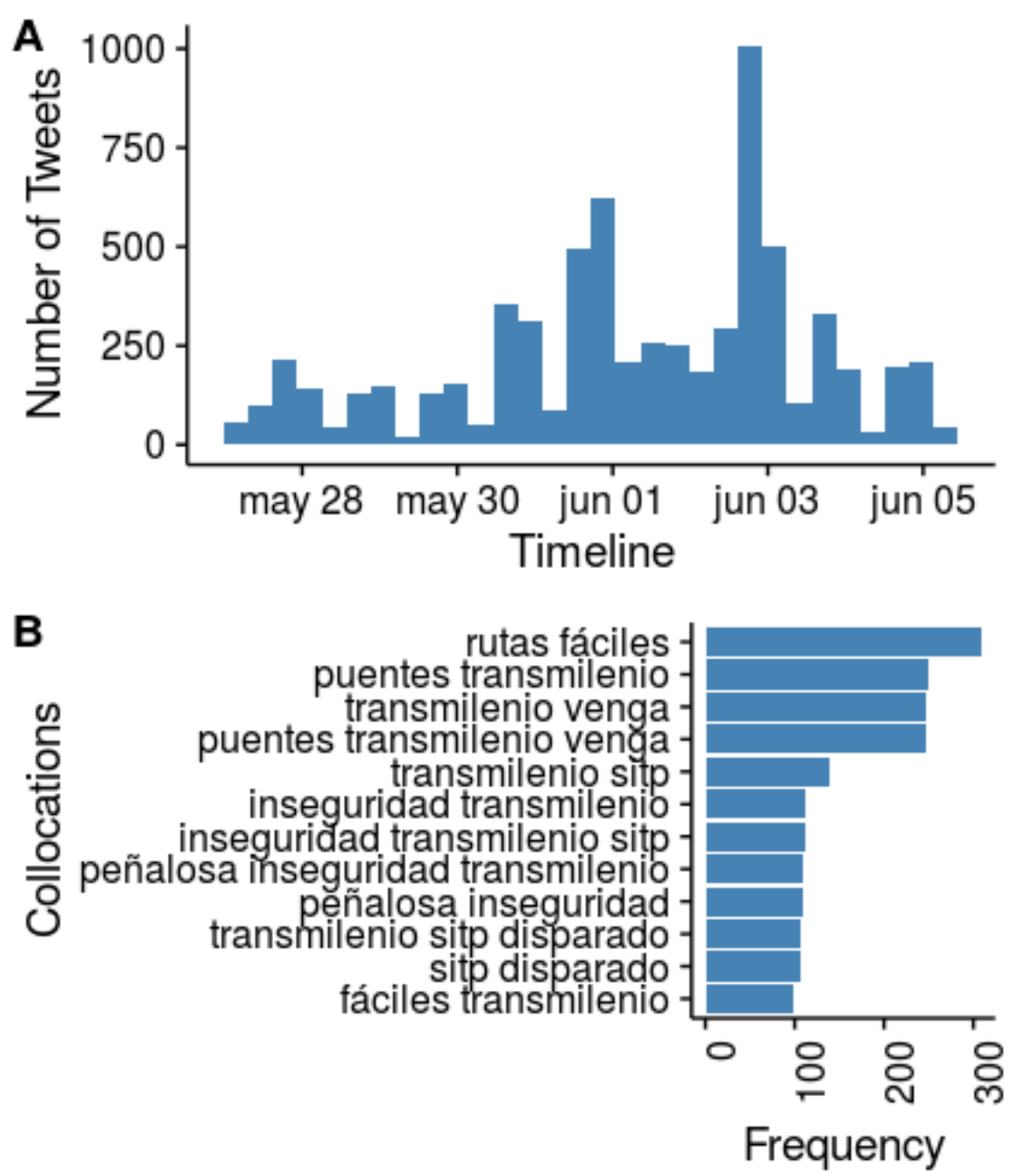

Figure 1. A) Daily Twitter users' activity containing the word Transmilenio, B) Words that co-occur with Transmilenio

Figure 2 depicts the relationship between the cost of different Uber services currently available in Bogotá and the distances of "random routes" between Transmilenio stations and a representative sample of shopping centers. This relationship proved to be neatly linear by the same time period of the tweets that included the word "Transmilenio" for the city of Bogotá. Nonetheless, it also reveals the fare differences among these Uber services. The cheapest Uber service was UberPOOL, while the most expensive was the UberVAN. Although in both cases, passengers share the same vehicle, in UberPOOL different destinations are allowed, while in UberVAN passengers also share a unique destination. 


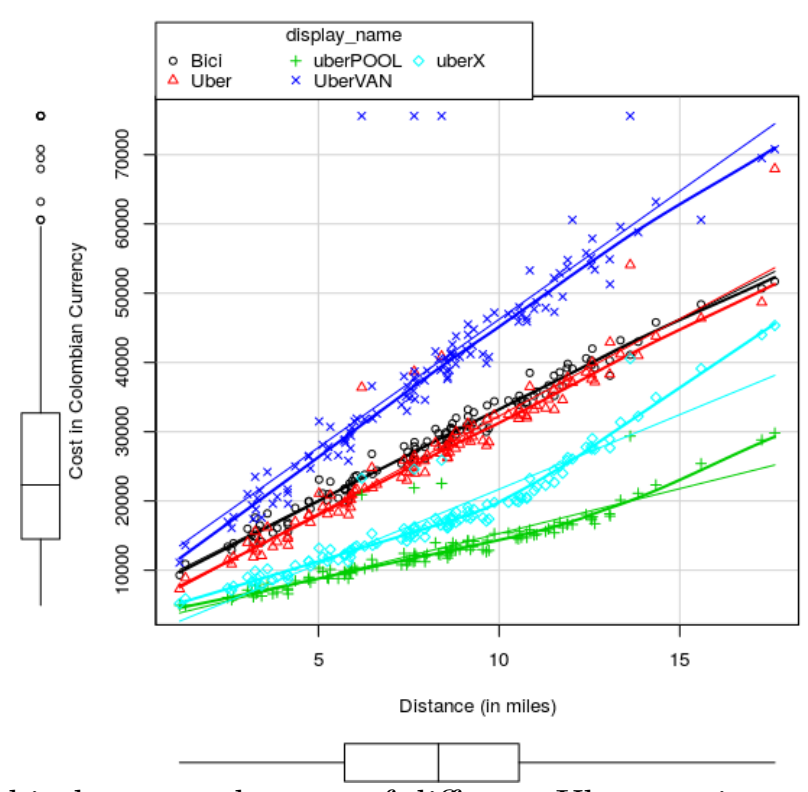

Figure 2. Relationship between the cost of different Uber services and distances

Figure 3 shows the statistical distributions of Google Maps estimated travel times for different transportation modes that can be used in the same time period of the tweets that contained the word "transmilenio". The figure reveals a consistent difference between the transportation mode choice $\left(\mathrm{F}=15,138 ; \mathrm{p}<0.01 ; \eta^{2}=0.83\right)$. In particular, the use of any type of Uber service implies a travel time $46.39 \%$ faster than walking from any Transmilenio station to any nearby shopping center, but Uber travel times are almost the same as those for a bicycle, given the usual traffic conditions in Bogota during rush hours.

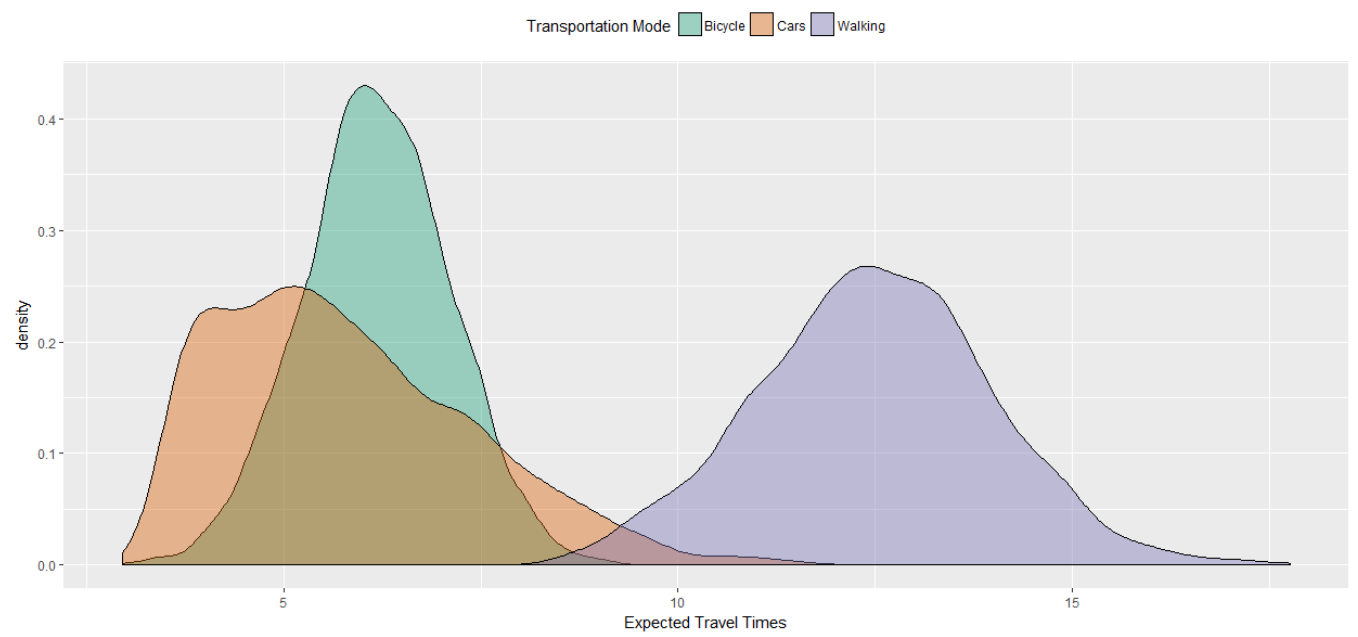

Figure 3. Statistical distributions of Google Maps estimated travel times for different transportation modes 


\section{Discussion}

Providing a rationale on why social networks can be both scientifically useful and socially relevant for consumer research was the aim of this paper. Compared with previous studies who also illustrated the relevance of social networks for consumer research (Heinonen, 2011; Correa \& Forero, 2017), our study provided the following specific contributions. Firstly, by taking the urban mobility of Bogotá, as a case study for collaborative consumption research, we showed possible relationships between urban mobility and consumer behavior that can be examined in the future by using social networks API's. This idea is not novel at all in the literature of consumer behavior (Correa \& Forero, 2017), but it offers unique opportunities for enriching the methods of consumer behavior researchers, given the fact that these tools are easy to implement within R ( $\mathrm{R}$ Core Team, 2017). The second contribution of this study relates to the use of novel variables and possible ways to analyze them for purposes of theory building. By understanding that Uber, Twitter and Google Maps can be used as urban mobility social networks that provide interesting, sensitive and almost instantaneous data sets that complement surveys (Danneman \& Heimann, 2014), we now have the possibility to contrast the differences between consumers spontaneous information (e.g., in EWOMS spread through Twitter) and survey-induced responses. Such an endeavor might be of great help to overcome the limitations in the epistemology and methodology of consumer research (Pham, 2013).

As we agree with the idea that cities could benefit from the research that focuses on rethinking how transportation services are delivered and consumed (Anderson et al., 2013), another contribution of this study is the possibility to use social networks like observatories of urban mobility patterns at the city scale. This approach is certainly useful as a data calibration technique for models of complex spatial shopping behavior (Rasouli \& Timmermans, 2013), and agent-based models of consumer behavior (Schenk, Löffler, \& Rauh, 2007). In addition, this approach might be used for transportation planning, given the possibilities to evaluate how traffic congestion affects the number of Uber requested services.

As a final comment, we foresee that future theories of consumer behavior will show interesting forms of articulating different data sources (i.e., experiments, surveys, simulations and social networks). Such theories will be the result of collaborating with colleagues from other disciplines like computer science and data science, given the fact that collaborative consumption platforms operate on web servers.

\section{References}

Anderson, L., Ostrom, A. L., Corus, C., Fisk, R. P., Gallan, A. S., Giraldo, M., .. others (2013). Transformative Service Research: An Agenda for the Future. Journal of Business Research. doi: $10.1016 / \mathrm{j} . j b$, usres.2012.08.013

Bardhi, F., \& Eckhardt, G. M. (2012). Access-based consumption: The case of car sharing. Journal of Consumer Research, 39(4), 881-898. doi: 10.1086/666376

Benoit, K., Watanabe, K., Nulty, P., Obeng, A., Wang, H., Lauderdale, B., \& Lowe, W. (2017). quanteda: Quantitative analysis of textual data [Computer software manual]. Retrieved from http://quanteda.io ( $\mathrm{R}$ package version 0.9.9-50) 
Benoit, S., Baker, T. L., Bolton, R. N., Gruber, T., \& Kandampully, J. (2017). A triadic framework for collaborative consumption (CC): Motives, activities and resources \& capabilities of actors. Journal of Business Research. doi: 10.1016/j.jbusres.2017.05.004

Bouveyron, C., Côme, E., Jacques, J., et al. (2015). The discriminative functional mixture model for a comparative analysis of bike sharing systems. The Annals of Applied Statistics, 9(4), $1726-1760$.

Chen, E. E., \& Wojcik, S. P. (2016). A Practical Guide to Big Data Research in Psychology. Psychological Methods, 21(4), 458-474. doi: 10.1037/met0000111

Chen, K., Luo, P., \& Wang, H. (2017). An influence framework on product word-of-mouth (wom) measurement. Information 83 Management, 54(2), 228-240.

Cheung, M. W.-L., \& Jak, S. (2016). Analyzing Big Data in Psychology: A Split/Analyze/MetaAnalyze Approach. Frontiers in psychology, 7. doi: 10.3389/fpsyg.2016.00738

Collier, A., \& Wu, A. (2017). ubeR: Interface to the Uber API [Computer software manual]. Retrieved from https://CRAN.R-project.org/package=ubeR (R package version 0.1.4)

Correa, J. C., \& Camargo, J. (2017). Ideological Consumerism in Colombian Elections, 2015: Links between Political Ideology, Twitter Activity and Electoral Results. Cyberpsychology, Behavior and Social Networking, 20(1), 37-43. doi: 10.1089/cyber.2016.0402

Correa, J. C., \& Forero, D. E. (2017). The Relevance of Urban Mobility for Consumer Research : An Interdisciplinary Perspective. In E. P. Becerra, R. Chitturi, M. C. Henriquez Daza, \& J. C. Londoño Roldán (Eds.), Latin American Advances in Consumer Research (pp. 101104). Cali, Colombia: Dulum, MN: Association for Consumer Research. Retrieved from http://www.acrwebsite.org/volumes/la/v4_pdf/laacr_vol4_1700055.pdf

Cramer, J., \& Krueger, A. B. (2016). Disruptive change in the taxi business: The case of uber. The American Economic Review, 106(5), 177-182. doi: 10.1257/aer.p20161002

Danneman, N., \& Heimann, R. (2014). Social Media Mining with R. Birmingham, UK: PACKT.

Englis, B. G., Solomon, M. R., \& Danskin, P. (2005). Web-Based Consumer Research. In C. P. Haugtvedt, K. A. Machleit, \& R. F. Yalch (Eds.), Online Consumer Psychology: Understanding and Influencing Consumer Behavior in the Virtual World (p. 491-510). New York: Lawrence Erlbaum Associates.

Evans, N. J., Phua, J., Lim, J., \& Jun, H. (2017). Disclosing instagram influencer advertising: The effects of disclosure language on advertising recognition, attitudes, and behavioral intent. Journal of Interactive Advertising, 1-12.

Feeney, M. (2015). Is ridesharing safe? Cato Policy Analysis, 767, 1-15.

Figueiredo, B., \& Scaraboto, D. (2016). The systemic creation of value through circulation in collaborative consumer networks. Journal of Consumer Research, 43(4), 509-533. doi: $10.1093 / \mathrm{jcr} / \mathrm{ucw} 038$

Forelle, M. C., Howard, P. N., Monroy-Hernández, A., \& Savage, S. (2015). Political bots and the manipulation of public opinion in Venezuela.

Gakenheimer, R. (1999). Urban mobility in the developing world. Transportation Research Part A: Policy and Practice, 33(7-8), 671-689. doi: 10.1016/S0965-8564(99)00005-1

Gentry, J. (2015). twitter: R based twitter client [Computer software manual]. Retrieved from https://CRAN.R-project.org/package=twitteR (R package version 1.1.9)

Gopaldas, A. (2014). Marketplace sentiments. Journal of Consumer Research, 41(4), 995-1014. doi: $10.1086 / 678034$

Hamari, J., Sjöklint, M., \& Ukkonen, A. (2016). The sharing economy: Why people participate in collaborative consumption. Journal of the Association for Information Science and Technology, 67(9), 2047-2059. doi: 10.1002/asi.23552

Hawelka, B., Sitko, I., Beinat, E., Sobolevsky, S., Kazakopoulos, P., \& Ratti, C. (2014). Geolocated twitter as proxy for global mobility patterns. Cartography and Geographic Information Science, 41(3), 260-271. doi: 10.1080/15230406.2014.890072 
Heinonen, K. (2011). Consumer activity in social media: Managerial approaches to consumers' social media behavior. Journal of Consumer Behaviour, 10(6), 356-364.

Hennig-Thurau, T., Gwinner, K. P., Walsh, G., \& Gremler, D. D. (2004). Electronic word-of-mouth via consumer-opinion platforms: What motivates consumers to articulate themselves on the internet? Journal of interactive marketing, 18(1), 38-52.

Henry, P. (2005). Is the Internet Empowering Consumers to Make Better Decisions, or Strengthening Marketers' Potential to Persuade? In C. P. Haugtvedt, K. A. Machleit, \& R. F. Yalch (Eds.), Online Consumer Psychology: Understanding and Influencing Consumer Behavior in the Virtual World (pp. 345-360). New York: Lawrence Erlbaum Associates.

Huang, Z., \& Benyoucef, M. (2013). From e-commerce to social commerce: A close look at design features. Electronic Commerce Research and Applications, 12(4), 246-259.

Kahle, D., \& Wickham, H. (2013). ggmap: Spatial visualization with ggplot2. The R Journal, 5(1), 144-161.

Kash, G., \& Hidalgo, D. (2014). The Promise and Challenges of Integrating Public Transportation in Bogotá, Colombia. Public Transport, 6, 107-135. doi: 10.1007/s12469-013-0083-7

Kozinets, R. V. (2015). Netnography: Redefined. London: Sage.

Kozinets, R. V., Patterson, A., \& Ashman, R. (2016). Networks of Desire: How Technology Increases Our Passion to Consume. Journal of Consumer Research, 43(5), 659-682. doi: $10.1093 /$ jcr/ucw061

Landers, R. N., Brusso, R. C., Cavanaugh, K. J., \& Collmus, A. B. (2016). A primer on theory-driven web scraping: Automatic extraction of big data from the internet for use in psychological research. Psychological Methods, 21(4), 475. doi: 10.1037/met0000081

Lee, D., Hosanagar, K., \& Nair, H. S. (2018). Advertising content and consumer engagement on social media: evidence from facebook. Management Science.

Lynch, J. G., Alba, J. W., Krishna, A., Morwitz, V., \& Gurhan-Canli, Z. (2012). Knowledge creation in consumer research: Multiple routes, multiple criteria. Journal of Consumer Psychology, 22, 473-485. doi: 10.1016/j.jcps.2012.06.004

Lynch, J. G., et al. (2015). Mission Creep, Mission Impossible, or Mission of Honor? Consumer Behavior BDT Research in an Internet Age. Journal of Marketing Behavior, 1(1), 37-52. doi: $10.1561 / 107.00000002$

Meyer, D., Hornik, K., \& Feinerer, I. (2008). Text mining infrastructure in r. Journal of Statistical Software, 25(5), 1-54.

Möhlmann, M. (2015). Collaborative consumption: determinants of satisfaction and the likelihood of using a sharing economy option again. Journal of Consumer Behaviour, 14(3), 193-207.

Montezuma, R. (2005). The transformation of Bogota, Colombia, 1995-2000: Investing in citizenship and urban mobility. Global Urban Development, 1(1), 1 - 10.

Parra, D. C., \& Lemoine, P. D. (2017). Walking for Transportation and TransMilenio in Bogotá: Strengths and Shortcomings. In Walking: Connecting sustainable transport with health (Vol. 9, pp. 347-363). Emerald Publishing Limited. doi: 10.1108/S2044-994120170000009019

Pham, M. T. (2013). The seven sins of consumer psychology. Journal of consumer psychology, $23(4), 411-423$.

R Core Team. (2017). R: A language and environment for statistical computing [Computer software manual]. Vienna, Austria. Retrieved from https://www.R-project.org/

Rasouli, S., \& Timmermans, H. (2013). Assessment of model uncertainty in destinations and travel forecasts of models of complex spatial shopping behaviour. Journal of Retailing and Consumer Services, 20(2), 139-146. doi: 10.1016/j.jretconser.2012.05.001

Restrepo, C., \& Salgado, E. (2013). Types of contracts and worker absenteeism in colombia. Journal of Business Research, 66 (3), 401-408. doi: 10.1016/j.jbusres.2012.04.006

Scaraboto, D. (2015). Selling, sharing, and everything in between: The hybrid economies of collaborative networks. Journal of Consumer Research, 42(1), 152-176. doi: 10.1093/jcr/ucv004 
Schenk, T. A., Löffler, G., \& Rauh, J. (2007). Agent-based simulation of consumer behavior in grocery shopping on a regional level. Journal of Business Research, 60(8), 894-903.

Simonson, I. (2015). Mission (Largely) Accomplished: What's Next for Consumer BDT-JDM Researchers? Journal of Marketing Behavior, 1, 9-35. doi: 10.1561/107.00000001 